\title{
O CORPO, A VIOLÊNCIA E A LIBERDADE EM ALGUNS POEMAS DE CESARINY
}

\section{BODY, VIOLENCE AND FREEDOM IN SOME CESARINY POEMS}

\author{
Raquel dos Santos Madanêlo Souza* \\ $U F M G$
}

Resumo: O objetivo deste estudo é refletir sobre os sentidos do corpo, da violência e da liberdade em alguns poemas do livro Pena Capital, de Mário Cesariny. Para isso, parte-se da leitura da tese de Maria de Fátima Marinho sobre o surrealismo em Portugal e de texto de Jaime Ginzburg sobre Adorno e a poesia em tempos sombrios. Os poemas do livro citado de Cesariny parecem propor que a liberdade do corpo, da linguagem e das formas literárias funcione como tentativa de superação do cerceamento político, em Portugal, durante o Estado Novo.

Palavras-chave: Corpo. Violência. Liberdade. Mário Cesariny.

\begin{abstract}
The aim of this study is to reflect on the senses of the body, violence and freedom in some poems in the book Pena Capital, by Mario Cesariny. For this, we start by reading Maria de Fátima Marinho's thesis on surrealism in Portugal and Jaime Ginzburg's text on Adorno and poetry in dark times. The poems of Cesariny's quoted book seem to propose that the freedom of the body, language and literary forms works as an attempt to overcome the political curtailment in Portugal during the Estado Novo.
\end{abstract}

Keywords: Body. Violence. Liberty. Mário Cesariny.

Em Pena Capital, livro do escritor português Mário Cesariny de Vasconcelos (1923-2006), as “MONSTRUOSIDADES COMO ESTA FAMOSA ‘CIVILIZAÇÃO OCIDENTAL' SOB A QUAL SUFOCAMOS” (CESARINY, 1982) é um dos versos-chave do penúltimo poema - todo escrito em caixa alta, com título em minúsculas -, chamado:

$$
\text { o regresso de ulisses }
$$

O HOMEM É UMA MULHER QUE EM VEZ DE TER UMA CONA TEM UMA PIÇA, O QUE EM NADA PREJUDICA O NORMAL ANDAMENTO DAS COISAS E ACRESCENTA UM TIC DELICIOSO À DIVERSIDADE DA ESPÉCIE. MAS O HOMEM É UMA MULHER QUE NUNCA SE COMPORTOU COMO MULHER, E QUIS DIFERENCIAR-SE, FAZER CHIC, NÃO CONSEGUINDO COM ISSO SENÃO PRODUZIR MONSTRUOSIDADES

\footnotetext{
${ }^{*}$ Doutora em Estudos Comparados de Literaturas de Língua Portuguesa, pela Universidade de São Paulo (2008) e Professora de Literatura Portuguesa da Universidade Federal de Minas Gerais. E-mail: raquelsmsouza@gmail.com
} 
COMO ESTA FAMOSA “CIVILIZAÇÃO OCIDENTAL” SOB A QUAL SUFOCAMOS MAS QUE, FELIZMENTE, VAI DESAPARECER EM BREVE.

PELO CONTRÁRIO, A MULHER, QUE É UM HOMEM, SOUBE SEMPRE GUARDAR AS DISTÂNCIAS E NUNCA PRETENDEU SUBSTITUIR-SE À VIDA SISTEMATIZANDO PUERILIDADES COMO FILOSOFIA, AVIAÇÃO, CIÊNCIA, MÚSICA (SINFÓNICA), GUERRAS, ETC. ALGUNS PEDANTES QUE SE TOMAM POR LIBERTADORES DIZEMNA “ESCRAVA DO HOMEM” E ELA RI ÀS ESCÂNCARAS, COM A SUA CONA, QUE É UM HOMEM.

DESDE O ÍNICIO DOS TEMPOS, ANTES DA ROBOTSTÓNICA GREGA, OS ÚNICOS HOMENS-HOMENS QUE APARECERAM FORAM OS HOMENS-MEDICINA, OS HOMENS-XAMÃS (HOMOSSEXUAIS ARQUIMULHERES). ÊSSES E AS AMAZONAS (SUPER-MULHERES-HOMENS). MAS UNS E OUTRAS ERAM DEMAIS DEMAIS. E DESDE O INÍCIO DOS TEMPOS QUE PENÉLOPE ESPERA O REGRESSO DE ULISSES. MAS O REGRESSO DE ULISSES É O HOMEM QUE É UMA MULHER E A MULHER QUE É UMA MULHER QUE É UM HOMEM. (CESARINY, 1982)

Além das evidentes e complexas questões de gênero, das proposições predicativas que subvertem a lógica mais tradicional da língua portuguesa e da estrutura peculiar do texto, a voz poética um tanto argumentativa afirma, em visível contentamento, o fim próximo daquele modelo civilizacional. Mas por que expressar felicidade diante do eminente desaparecimento do Ocidente? O livro em questão, amplo, complexo e diverso, tanto do ponto de vista temático quanto formal, aponta para algumas hipóteses que podem ser analisadas a partir da investigação de elementos relacionados ao corpo, à liberdade e à violência, tópicos que aparecem distribuídos ao longo de alguns dos 84 textos que compuseram a edição da obra lançada, primeiramente, em 1957, e ampliada pelo poeta, em nova publicação de 1982.

O primeiro poema do livro, intitulado “notícia”, que ao contrário do citado anteriormente é todo escrito em letras minúsculas, apresenta um sujeito que assume uma postura um tanto desdenhosa e blasé, semelhante à da voz de “Manucure”, de Mário de Sá-Carneiro:

notícia

\author{
Enquanto três camelos invadiam o aeroporto do Cairo e o pessoal \\ de terra loucamente tentava apanhar \\ os animais \\ eu limpava as minhas unhas \\ quando acabava de ser identificada a casa onde viveu \\ Miguel Cervantes, em Alcalá de Henares, \\ eu saía para o campo com Rufino Tamayo \\ enquanto um português vivia trinta anos com urna bala alojada \\ num pulmão \\ chegava eu ao conhecimento das coisas \\ Report this ad \\ Agora já não há braseiros e os destroços foram removidos
}


os animais espantaram-se

e como se isso não fosse desde já um admirável e surpreendente

esforço na nossa acção de escritores

afogado num poço canta um homem

ORADOUR-SUR-GLANE

Gritos brancos gritos pardos gritos pretos

não mais haverá braseiros - os destroços foram

removidos

E não esquecendo o esforço daquele outro

que para aquecer o ambiente apareceu morto

e não enviou convite nem notícia a ninguém

Mundo mundo vasto mundo

(Carlos Drummond de Andrade)

os conspiradores conspiram

os transpiradores transpiram

os transformadores aspiram

e Deus acolhe tudo num grande cesto especial

A lei da gravidade dos teus olhos, mãe,

a lei da gravidade aqui está: é um poeta

num barco a gasolina não não não é um operário

com um martelo na mão muito depressa

os automóveis passam o rapazio grita

o criado serve (se não servisse, morria)

os olhos em vão rebentam a pessoa levantou-se

tantas crianças meu Deus lá vai o meu amor

Também ele passou trezentas vezes a rampa

- que estranhas coisas passaram! Os poetas é que

sabem

construção construção

progresso no transporte

ORADOUR-SUR-GLANE

Souviens-toi

REMEMBER (CESARINY, 1982) 
Enquanto "limpava” as suas “unhas”, fatos estranhos, inverossímeis ${ }^{1}$ e, a princípio, desencontrados - como o aparecimento de um camelo ${ }^{2}$ no aeroporto do Cairo e a identificação da casa de Cervantes em Alcalá - faziam com que se chegasse "ao conhecimento das coisas”. Mas quando lemos o verso “Agora já não há braseiros - os destroços foram/ removidos”, aquele eu inicial que parecia algo distante e indiferente diante do que o cercava, passa a ser um sujeito que aponta, em tom de ironia, para o “esforço" “admirável e surpreendente” da ação dos “escritores” frente aos acontecimentos correntes. No meio do texto, um verso em caixa alta, formando uma única estrofe, torna-se evidente em meio às letras em formato menor: “ORADOUR-SUR-GLANE" (CESARINY, 1982). Essa expressão que dá nome à aldeia francesa vitimada pelo massacre de seus habitantes durante a segunda guerra Mundial é o destaque formal e semântico do poema de Cesariny. Homens fuzilados e queimados em celeiros; mulheres e crianças também queimadas na Igreja da Aldeia e um total de mais de 600 pessoas massacradas em 1944. Esse é o relato que se encontra registrado na história do pequeno povoado. Mas no poema lido, há apenas a figuração do nome daquela cidade e a referência, metonimicamente repetida, aos "braseiros", que não mais existirão, já que os destroços - restos humanos e materiais fundidos pelo fogo foram removidos. Além dessa imagem, temos em outra estrofe um lamento em tom interjectivo: “tantas crianças meu Deus”, que pode ser uma referência aos infantes também vitimados pela violência daquela guerra. Na sequência, um verso do "Poema de sete faces" é textualmente citado: "Mundo mundo vasto mundo" / (Carlos Drummond de Andrade)" (CESARINY, 1982), e, na linha seguinte, o nome do escritor mineiro surge inserido entre parênteses. Do poema de Drummond, o que poderia aproximar-se daquela tragédia? Um sujeito que se sente fraco, impotente e abandonado por "Deus” no “vasto mundo”? Ou um poeta que ao invés de uma rima para seus versos buscaria uma solução? Sem obter as respostas que possam ser sugeridas, a leitura prossegue por um texto complexo e pouco afeito a elaborações lógicas:
a lei da gravidade
aqui está
é um poeta
num barco a gasolina não não não
é um operário
com um martelo na mão muito depressa

A forma visual, bastante recorrente e evidente no poema e no livro, isola uma expressão que localiza, num aqui e agora imprecisos, a identificação entre a lei da gravidade e um poeta em um barco veloz. Em seguida, o advérbio de negação também isolado é repetido por três vezes, e a gravidade, agora, é o operário, com um martelo na mão (e talvez uma foice? Poderia perguntar o leitor). Essa lei, que ao que parece fala não da atração entre os corpos, mas sim do peso inerente à situação de guerra figurada ali, traz no poeta e no operário duas forças que poderiam atuar nessa realidade. Mas a vida continua e o quotidiano se sobrepõe ao horror da guerra, a despeito da tragédia destacada nos versos. Retornando ao título, pode-se pensar que as notícias variadas de um jornal pouco convencional aparecem justapostas, ao lado daquilo que poderia ser ali uma manchete, em caixa alta: o nome da cidade francesa, repetido mais uma vez nos versos finais do poema. Na sequência, e também como uma estrofe de apenas

\footnotetext{
${ }^{1}$ Ao falar sobre o Surrealismo em Portugal e sobre a obra de Mário Cesariny, Maria de Fátima Marinho afirma que haveria em parte da produção do poeta um: "caos provocado por imagens devedoras de uma poética diretamente influenciada pelas doutrinas francesas de André Breton”(...). ( MARINHO, p. 338).

${ }^{2}$ Maria de Fátima Marinho aponta para o “inverossímil” em Pena capital.
} 
um verso e escrito em francês: "Souviens-toi” e, por último, um verso isolado e sinônimo ao anterior, mas em língua inglesa: REMEMBER. Nesse sentido, é possível deduzir que o poema “notícias” aborda a violência do massacre, que figuraria misturado a informações variadas, que banalizariam a gravidade do evento; mas ao tornar-se matéria de um poema, na obra de Cesariny, teríamos um processo de eternização dos horrores da guerra, através da ação do poeta e da ação dos leitores diante da obra e da constante atualização desse horror que é proporcionada pelas leituras realizadas pelo público.

Já em “vinte quadras para um dadá II”, temos um eu que se sente perdido numa espécie de desconcerto íntimo, cuja tradição parece ligar-se, na história da literatura portuguesa, à do poema "Comigo me desavim”, do escritor seiscentista Sá-de-Miranda. Essa formulação intimista, que aparece no poema do escritor surrealista através dos versos: "Eu estou presente/ todo eu sou sim/ e é de repente/ não dou por mim” (CESARINY, 1982), aponta ainda para outra leitura da tradição lusitana, que se desdobra na representação do sujeito, na modernidade, na conhecida quadra de Mário de Sá-Carneiro ${ }^{3}$, no poema 7, e cujo primeiro verso afirma: "Eu não sou eu nem sou o outro”. E não é à toa que se faz, novamente, a aproximação entre a poesia de Cesariny e a do escritor modernista, na análise aqui proposta, já que na nona quadra temos os versos que explicitam a referência intertextual por meio do quarteto: "Os ébrios, êsses/ passam de largo/ Ai Sá-Carneiro/ Carneiro amargo”4. E, para além desse desencontro consigo mesmo, representado nesse poema e em vários outros de Pena capital, temos um eu que não se sente apenas narcisicamente autocentrado em sua subjetividade, mas que olha com desprezo para a realidade histórica portuguesa: “Fui-me à de lata/ sangrenta escura/ patrícia pata/ da dita dura”. Há uma representação de descaramento ou ousadia na atitude paródica do sujeito, através do uso da expressão coloquial "Fui-me à de lata". E nesse gesto atrevido, descreve-se o governo ditatorial como um corpo animal, metonimicamente representado pela "pata” "patrícia” da formalmente satirizada, sonoramente rimada e desconstruída "dita dura”. Contra essa forma de governo, são elaboradas perguntas que colocam em questão a ação das "burguesinhas” e dos “vizinhos”: “Sabeis lutar?/ Sabeis perder?/ Viver? Morrer?/ Que heis-de fazer?”. Mas parecendo não ter ainda respostas a essas questões, o poema é finalizado com a retomada das ideias expressas nos versos iniciais que, no entanto, figuram um sujeito que parece modificado e melancólico e que desejaria ser antes incapacitado de ver, apesar de se mostrar desejoso de estar: "Pois no que vi/ não ver é que há/ e eu estou ali/ não estando lá”. O desejo de distanciamento da situação pode ser interpretado como o de um sujeito que pretende alcançar o fim ditadura, de modo a não ser obrigado a ver o que não quer; e que se encontre em uma situação em que se possa estar pleno e por inteiro, e não cindido, como nos primeiros versos deste poema e nos versos de Miranda e Sá-Carneiro.

\footnotetext{
${ }^{3}$ Outra referência explícita a Mário de Sá-Carneiro encontra-se no poema “ode a outros e a maria helena vieira da silva”, cujo último verso é: “nossa nossa senhora de Paris”. “Nossa Senhora de Paris” é um dos poemas do livro Indícios de Oiro, publicado postumamente à morte do poeta Sá-Carneiro.

${ }^{4}$ Para José Cândido Martins, da Universidade do Minho, haveria uma relação parodística entre o poema de Cesariny e a “Dispersão”, de Sá-Carneiro.
} 
Já na segunda parte do livro, temos um dos poemas mais emblemáticos de Cesariny: "You are welcome to Elsinore".

Entre nós e as palavras há metal fundente entre nós e as palavras há hélices que andam e podem dar-nos a morte violar-nos tirar do mais fundo de nós o mais útil segredo entre nós e as palavras há perfis ardentes espaços cheios de gente de costas altas flores venenosas portas por abrir e escadas e ponteiros e crianças sentadas à espera do seu tempo e do seu precipício

Ao longo da muralha que habitamos há palavras de vida há palavras de morte há palavras imensas, que esperam por nós e outras, frágeis, que deixaram de esperar há palavras acesas como barcos e há palavras homens, palavras que guardam o seu segredo e a sua posição

Entre nós e as palavras, surdamente, as mãos e as paredes de Elsinore

E há palavras nocturnas palavras gemidos palavras que nos sobem ilegíveis à boca palavras diamantes palavras nunca escritas palavras impossíveis de escrever por não termos connosco cordas de violinos nem todo o sangue do mundo nem todo o amplexo do ar e os braços dos amantes escrevem muito alto muito além do azul onde oxidados morrem palavras maternais só sombra só soluço só espasmos só amor só solidão desfeita

Entre nós e as palavras, os emparedados e entre nós e as palavras, o nosso dever falar 
Como aponta Perfecto Cuadrado no livro Século de Ouro, o título do poema remete para o Hamelet de Shakespeare, quando no Ato II, Hamlet dá as boas-vindas, no castelo de Elsinore, aos velhos amigos Rosencratz e Guildesnstern, convocados pelo Rei sob o pretexto da 'loucura' do Príncipe e destinados a ser os seus carrascos (sem eles o saberem) para serem afinal (sem eles suspeitarem) as suas vítimas. (CUADRADO, 2002).

Para Cuadrado, a convocação desse lugar, dentro da obra de Cesariny, deve-se ao contexto português da ditadura salazarista e das consequentes misérias da prisão. O poema iniciado pelo verso "Entre nós e as palavras”, que se constitui em uma anáfora, que é repetido ainda por quatro vezes ao longo das estrofes, representa o abismo existente entre o ser e a palavra. Além disso, é importante destacar ainda que o vocábulo “palavras” é utilizado 18 vezes nos 30 versos livres e sem rimas desse texto, que apresenta uma sonoridade que se evidencia pela repetição nada gratuita dessas estruturas lexicais. Essa repetição, algo excessiva, fala, em primeiro lugar, do que há entre o "nós” e as palavras: "metal fundente”, "hélices que andam”, "mãos e paredes de Elsinore”, “os emparedados” e, por fim, mas não menos importante: “o nosso dever falar”. Entre os sujeitos e a linguagem, uma forma de poder capaz de "dar-nos morte violar-nos tirar/ do mais fundo de nós o mais útil segredo"; ou seja, a existência de uma força capaz de empreender a violação do corpo a fim de extrair uma confissão, o que figuraria uma das formas de violência praticadas por um sistema ditatorial. Na estrofe seguinte, a "muralha que habitamos" tem palavras, de “vida”, “morte”; "imensas” e “frágeis”; "palavras homens”, agora justapostos, apontando para uma sinonímia entre ser e falar: "palavras que guardam/ o seu segredo e a sua posição”. Na terceira estrofe, “as mãos e as paredes de Elsinore”, quer dizer, a prisão que conduz os emparedados à busca de superação da violência: “o nosso dever falar”.

Esses versos reverberam outros versos de Pena capital, como em "poema”, em que o eu parece silenciado à força: “A minha boca/ perdeu a memória/ não pode falaras palavras”. O sentimento de cerceamento figurado pelas muralhas e paredes de Elsinore e de supressão do direito à palavra, já mencionado anteriormente, aparece ainda em "autoractor”, que tem na plateia de uma pretensa peça teatral, a presença de uma "metralhadora”, "nobre”, figura que aparece antes mesmo da estreia do espetáculo. E na ação que se encena, busca-se garantir aos atores apenas a liberdade de poder atuar: "Entre o amor que mata e o amor que se mata/ descem rápido o pano do $4^{\circ}$ acto/ é o fim/ contanto que nos deixem representar ainda”. Como se vê, é preciso ter permissão para representar, mesmo que apenas no ensaio, especialmente quando se tem como público privilegiado uma arma capaz de calar os corpos que encenam.

Mas haverá alguma saída, em Pena capital, que se sobreponha à guerra, a esse silenciamento, à prisão e à violência? Em “a carta em 1957”, poetas e jornalistas, atentos aos “trabalhos eleitorais” que antecediam as eleições presidenciais de 1958, teriam um projeto: “Um Plano!/ exclamaram os poetas politas de Lisboa/ sabe deus se conforme/ com a excelsa dignidade que nos leva/ neste momento da consciência humana/ às eleições igualmente grandiosas” (CESARINY, 1982). E o poeta que realizava traduções de Rimbaud e produzia outros trabalhos voltados à literatura, se encena no texto premindo os “intestinos” (CESARINY, 1982): “A barriga é que estava cada vez pior/ a um febrão sucedia-se outro/ com mais sal e pimenta à volta do prato limpo/ os graves problemas da pátria enferma/ como que coincidiam (na região do corpo/ co’aquela aguda sensação de desgraça”. Nesses versos, o poeta e a pátria encontram-se profundamente doentes. As escolhas lexicais que compõem o quadro apresentado apontam para essa relação 
intestina entre o escritor e sua nação, denotando desprezo e incômodo expressos por meio do uso de verbos como "evacuar" e "vomitar" as "coisas más” de que desejava se desfazer. Mas em seguida a aproximação entre pátria e poeta é relativizada: "Diga-se agora em abono da verdade/ que um poeta nem sempre é tal qual uma pátria/ não tem hotéis nem caminhos de ferro/ nem imprensa por ele nem ordenado”. E o “plano” forjado por ele, de "louvar o ser amado/ ter amigos leais/ escrever (...)/ publicar/ e protestar", ou como reforça ainda, "Este plano tão simples e tão nacional/ é que ficara longe da realização/ para amar com decência eram precisas muitas muitas [coisas”. A aparente simplicidade do projeto esboçado encontraria, porém, muitos obstáculos; e aquele que se decidisse, por exemplo, a protestar, teria de arcar com as consequências decorrentes de um "pau” brutalmente lançado contra sua cabeça.

Vale destacar, ainda, algumas outras figurações do poeta na obra analisada. Em "pena capital”, poema que dá título ao livro, há um “Poeta, exorcismando no seu atelier nos astros”, representando o escritor que brada das alturas, a uma distância maior até que a daquele artista isolado na "torre de marfim”; já em "notícia”, como vimos anteriormente, há um sujeito que parece questionar a viabilidade de "ação" dos “escritores” diante da guerra. Neste sentido, seja estando próximo aos acontecimentos, ao forjar um simples plano de ação, como em “ a carta de 1957”, por exemplo; seja distanciado dos acontecimentos, ao isolar-se entre os corpos celestes ou ao desejar não ser obrigado a ver tudo o que se passava a seu redor, o que percebemos no livro é a formulação de um questionamento constante sobre o significado e o poder da palavra e do poeta em tempos de sombrios ${ }^{5}$.

Em “corpo visível”, porém, parece afigurar-se uma esperança, ainda que vaga, de liberdade: "os dois amantes que hoje não dormiram vão partir/ nos braços da sua estrela”. E ainda, de forma explícita, "Livres/ digo Livres/ e isso não é só a grande rua sem fim por onde vamos/ viemos/ ao encontro um do outro". A possibilidade de se libertar estaria no "Amor/ amor humano/ amor que nos devolve tudo o que perdêssemos”. Ocorre, porém, que nem mesmo o corpo parece livre àqueles que vivem em sociedade. Sobre isso, lemos em "Um poema de Luís Cernuda”, que fala sobre a relação amorosa entre Rimbaud e Verlaine, uma voz poética que afirma: "Mas a liberdade não é deste mundo, e os libertos/ Em ruptura com todos, tiveram de pagá-la por alto/ Preço”(CESARINY, 1982)

A liberdade seria, portanto, algo ainda inalcançável neste mundo. Quanto a essa ideia, ainda, vale a pena referir os versos finais de “um canto telegráfico" em que se lê:

O AMOR REDIME O MUNDO diziam eles/ mas onde está o mundo senão aqui? (CESARINY, 1982)

Sobre esta pergunta final, parece que não há a formulação de uma resposta neste poema. Mas diante desse mundo que aparece representado em Pena capital, em que a guerra, a ditadura e a sociedade submetem as pessoas a diversas formas de violência, faz sentido verificar o contentamento do sujeito de "o retorno de Ulisses" que descrevia o desejo do fim da monstruosa “'CIVILIZAÇÃO OCIDENTAL’ SOB A QUAL SUFOCAMOS MAS QUE, FELIZMENTE, VAI DESAPARECER EM BREVE”.

O fim desse modelo civilizacional, inserido na era de extremos, nas palavras de Hobsbawn, seria, então, a única resposta possível para se fugir do ambiente sufocante e brutal desse Ocidente

${ }^{5}$ GINZBURG, 2003. 
em crise. E o que se pode verificar a partir da leitura de Pena capital, de Mário Cesariny, é a maneira como se dá o “empenhamento revolucionário” (GUIMARÃES, 2004) do Surrealismo, a partir da busca constante pela liberdade do corpo, da linguagem e das formas literárias e, também, do amor, como formas de superação das brutalidades das guerras e das ditaduras.

\section{Referências}

CESARINY, Mário. Pena capital. Lisboa: Assírio e Alvim, 1982.

CUADRADO, Perfecto. Estudo - "You are welcome to Elsinore”. In: SILVESTRE, Osvaldo M.; SERRA, Pedro (Orgs.) Século de Ouro. Antologia Crítica da Poesia Portuguesa do Século XX. Lisboa: Cotovia; Coimbra: Angelus Novus, 2002. 666 p.

GUIMARÃES, Fernando. Simbolismo, modernismo e vanguardas. Lisboa: Imprensa Nacional Casa da Moeda, 2004.

GINZBURG, Jaime. Theodor Adorno e a poesia em tempos sombrios. Alea: Estudos Neolatinos, Rio de Janeiro, v. 5, n. 1, p. 61-69, 2003.

HOBSBAWN, Eric. A era dos extremos: o breve século XX. 2 ed. São Paulo: Companhia das Letras, 1997.

MARTINS; José Cândido. A paródia Carnavalesca no Surrealismo Português e a teorização de Mikhail Bakhtin, in Letras\&Letras, s/d. Disponível em: http://alfarrabio.di.uminho.pt/vercial/ letras/candid06.htm. Acesso em: 31 ago. 2019.

MARINHO, Maria de Fátima. O surrealismo em Portugal. Lisboa: Imprensa Nacional Casa da Moeda, 1987.

TELES, Gilberto Mendonça. Vanguarda Europeia e Modernismo Brasileiro. Petrópolis, R.J.: Vozes, 1997.

Recebido em agosto/2019.

Aceito em outubro/2019. 